\title{
Irrupciones feministas en el arte antifranquista. La dimensión de lo político en María Franciska Dapena
}

\author{
Ane Lekuona Mariscal \\ Universidad del País Vasco \\ ane.lecuona@ehu.eus
}

RESUMEN: María Franciska Dapena (1924-1995) fue una artista multidisciplinar vizcaína recordada, por lo general, por su participación -la única femenina- en el colectivo de Estampa Popular de Vizcaya (1962), movimiento vertebrador de la historia del arte del siglo XX español y vasco. No obstante, su reconocimiento como integrante de este proyecto colectivo ha sido fruto de las investigaciones realizadas en las últimas décadas, donde se ha incorporado el objetivo de recuperar la agencia de mujeres artistas del pasado. En esta ocasión, el artículo trata de analizar, en primer lugar, la figura y obra de Dapena a través de una lectura de género y, a su vez, relacionar parte de su producción con el movimiento feminista que iba tomando forma en los círculos cercanos a la artista donde participaron, por ejemplo, Lidia Falcón o Sol Panera.

PALABRAS CLAVE: Arte antifranquista; Historia del feminismo; Partido Comunista; Estampa Popular de Vizcaya; Arte y política; Estudios de género; María Franciska Dapena.

\section{The Irruption of Feminisms in Anti-Franco Art. Notes on the Dimension of Politics in María Franciska Dapena}

ABSTRACT: María Franciska Dapena (1924-1995) was a multidisciplinary artist from Vizcaya remembered, generally, for her participation -the only woman- in the artistic group Estampa Popular de Vizcaya (1962), a backbone movement of legitimated Spanish and Basque art history of the 20th century. However, her recognition as a member of this collective project has been the result of researches carried out in recent decades, which incorporated the objective of recovering the agency of women artists of the past. On this occasion, the article attempts to analyse, firstly, the figure and work of Dapena through a gender perspective and, in turn, to relate part of her contribution to the feminist movement that was taking shape in the circles closest to the artist in which, for example, Lidia Falcón or Sol Panera participated.

KEYWORDS: Anti-Franco art; History of feminism; Communist Party; Estampa Popular de Vizcaya; Art \& politics; Gender studies; María Franciska Dapena.

Recibido: 10 de febrero de 2020 / Aceptado: 7 de junio de 2020.

\section{Negociando su lugar en el relato}

El caso de María Franciska Dapena (1924-1995) resulta interesante para evidenciar algunos de los cambios que se han ido produciendo en las últimas décadas dentro de la disciplina de la historia del arte, tanto en el marco estatal como en el contexto vasco. Para rescatar las primeras referencias escritas hacia la artista, es necesario retroceder a la crítica comprometida que surgió a partir de los años sesenta, la cual, en rechazo de la interpretación esteticista que se había generalizado hasta el momento, abogaba por introducir la problemática social como parámetro interpretativo de los objetos artísticos. Con esta aproximación, estos críticos justificaban el valor o la potencialidad vanguardista de los grupos políticamente comprometidos como, por ejemplo, Estampa Popular, agrupación a la que perteneció Dapena'. Ahora bien, como evidenciaba Noemí de Haro, los criterios en los que se sustentaba esta escritura se nutría de una visión fuertemente machista (2013).

Cómo citar este artículo: LEKUONA MARISCAL, Ane, «Irrupciones feministas en el arte antifranquista. La dimensión de lo político en María Franciska Dapena», Boletín de Arte-UMA, n. ${ }^{\circ}$ 41, Departamento de Historia del Arte, Universidad de Málaga, 2020, pp. 103-115, ISSN: 0211-8483, e-ISSN: 2695-415X, DOI: http://dx.doi.org/10.24310/ BoLArte.2020.v41i.7791 
Entre los ejemplos sexistas que apelaban directamente a la artista, encontramos, por ejemplo, la mención de Valeriano Bozal afirmando que «María Dapena sigue punto por punto los caminos abiertos por lbarrola» (1966: 120). Por su parte, José María Moreno Galván destacaba el supuesto carácter femenino de las obras de Dapena, interpretación que empequeñecía el carácter serio y políticamente comprometido que requería esta crítica.

María Francisca Dapena es menos fuerte. Es que es muy difícil tener la fortaleza de Ibarrola. Poseerá, sin duda, alguna otra virtud teologal, tal vez la de la templanza. ¿Sería un tópico decir que sus grabados son muy femeninos? (como se cita en: Makazaga, 2014).

Por consiguiente, los primeros trabajos que trataron de recuperar la figura de la artista, los cuales vendrían a partir de 2010, intentaron rescatar el papel de Dapena como integrante de Estampa Popular de Vizcaya y algunos también evidenciar los criterios machistas que había mantenido la historiografía ${ }^{2}$. Dentro de la primera línea encontramos trabajos de diferentes investigadoras ${ }^{3}$, las exposiciones en torno a Estampa Popular ${ }^{4}$ o, fundamentalmente, las recientes exposiciones retrospectivas realizadas en la localidad donde creció ella ${ }^{5}$. Ecos de este cambio se advertían, asimismo, en el hecho de que museos reconocidos adquirieran ${ }^{6} \mathrm{o}$ incluyeran obra de Dapena en diferentes exposiciones retrospectivas $^{7}$.

Por lo tanto, se ha ido recuperando la figura de María Dapena, principalmente como artista fundacional de Estampa Popular de Vizcaya ${ }^{8}$, de modo que sus obras han interesado y han sido interpretadas bajo este único marco, es decir, como manifestaciones de denuncia contra la represión franquista y las desigualdades del sistema. Sin embargo, como anticipaba De Haro, María Dapena también se interesó por la posición de las mujeres en la sociedad (2013) y, como veremos, sus vivencias le llevaron a desarrollar con el paso del tiempo una clara conciencia feminista. Así pues, las siguientes páginas tratan de analizar, por una parte, la figura de Dapena desde una perspectiva de género y, a su vez, relacionar parte de su obra con la nueva mirada que fue desarrollando la artista, lo que se vincula directamente con el resurgimiento del movimiento feminista en España a partir de los años sesenta.

\section{La conciencia política}

Como consecuencia de esta línea historiográfica, una de las cuestiones que más ha interesado en la figura de María Franciska Dapena ha sido el origen de su fuerte inclinación política, la cual debe ser relacionada con el pasado político familiar y con la experiencia vivida en los años de guerra e inmediata posguerra ${ }^{9}$. Sin embargo, fue a mediados de la década de los cuarenta cuando, alejándose de la inclinación socialista familiar, la artista se volcó en el Partido Comunista de Euskadi, en un momento en que solo este partido ofrecía un espacio de actuación contra la dictadura. No obstante, tal conciencia política todavía no se trasladaría a su planteamiento artístico, pues, por entonces, Dapena realizaba cuadros al óleo en un estilo impresionista, representando temas que, como el paisaje, los retratos familiares o los bodegones, encajaban con el rol de la mujer pintora del momento. Lo mismo ocurría con la forma de adentrarse en el sistema artístico del momento: siguió el esquema establecido de participar en los concursos y bienales que surgían dentro del circuito artístico vizcaíno ${ }^{10}$. Sería a partir de 1951 , tras conocer a Agustín Ibarrola y establecer contacto con un determinado círculo de artistas progresistas de la Asociación Artística Vizcaína, cuando pasó a entender el arte no como un ejercicio estético, sino como una extensión de su práctica política (Barrio y Pereda, 2016a: 29-32).

Esta visión se fue evidenciando, por ejemplo, en la tentativa que siguieron Agustín Ibarrola, Ismael Fidalgo, María Dapena y algunos poetas, al organizar entre 1955-1956 diferentes exposiciones y tertulias por los pueblos periféricos vizcaínos, con el objetivo de expandir la esfera de la cultura a estos espacios (Angulo, 1978: 65-66). Pero estilísticamente, este nuevo enfoque social se evidenciaba más claramente con la entrada del grabado. Fue precisamente a partir del regreso de París de Ibarrola, en 1961, cuando este introdujo la técnica de la xilografía a sus compañeros, al igual que los planteamientos del grupo Estampa Popular, dando así inicio al subgrupo vizcaíno (De Haro, 2010: 180). Con el grabado, el colectivo accedía a la reproducción de imágenes de una manera más económica, lo que favorecía el propósito de propagar sus obras fuera de los espacios artísticos tradicionales, a la vez que permitía la creación y difusión de un material visual que fuera crítico con el Régimen ${ }^{11}$. En cuanto a la iconografía empleada por Dapena en esta época, sus 


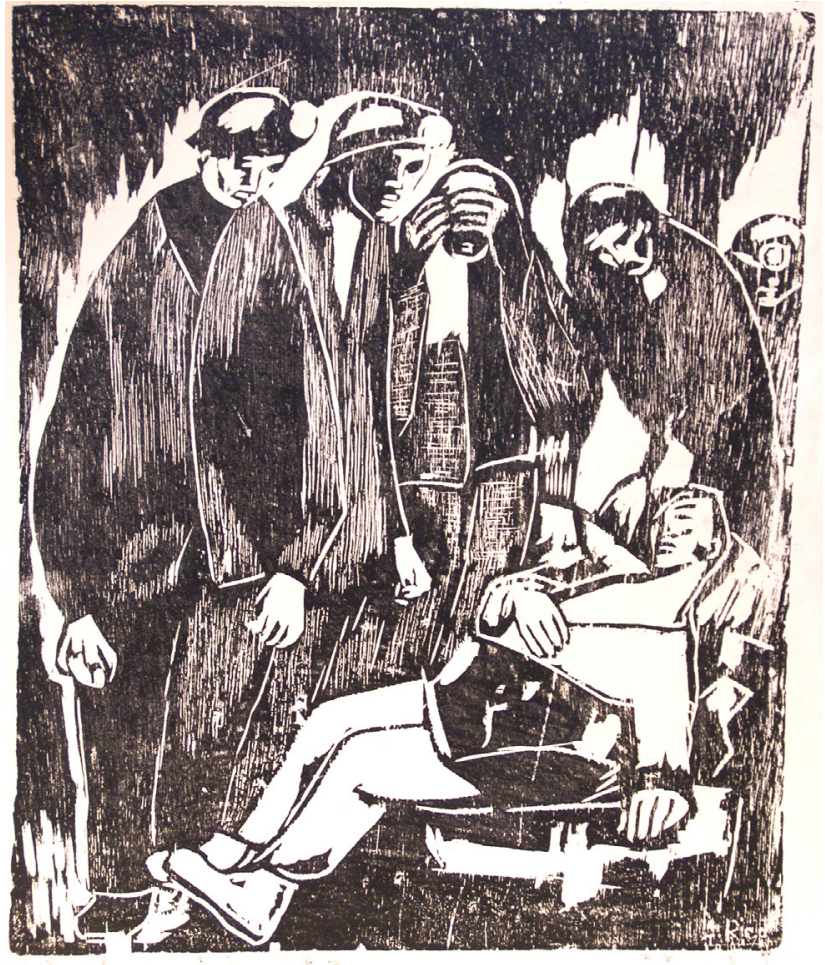

1. María Franciska Dapena, Sin título, linograbado sobre papel. Estampa Popular de Vizcaya. Hacia 1962. Propiedad de Gaizka Villate Dapena. Aporte de Museo de las Encartaciones-Juntas Generales de Vizcaya

grabados se relacionaban con el mundo obrero, siendo sus principales protagonistas los mineros, los obreros de la industria, los pescadores o las tejedoras. La forma de representarlos era a través de una figuración realista con matices expresionistas, exagerando algunas partes de la anatomía como los brazos o las manos, en referencia a la fuerza de los y las trabajadoras (Makazaga, 2014). Asimismo, la inclinación abertzale defendida por el PCE-EPK ${ }^{12}$ se percibía en la representación del mundo proletario vasco como los pescaderos o los mineros, diferente a la iconografía planteada por otros colectivos de Estampa Popular (García-Landarte, 2006) [1] y [2].

Sobre el tema que nos interesa ahora, es destacable que además de los protagonistas del mundo obrero, desde sus inicios Dapena representara asiduamente a niños y a figuras femeninas, por lo general, en escenas relacionadas con la maternidad (Barrio y Pereda, 2016b: 7). De ahí que Leire Makazaga interpretara estas representaciones como un «anhelo por conseguir un futuro mejor» (2014), relacio-

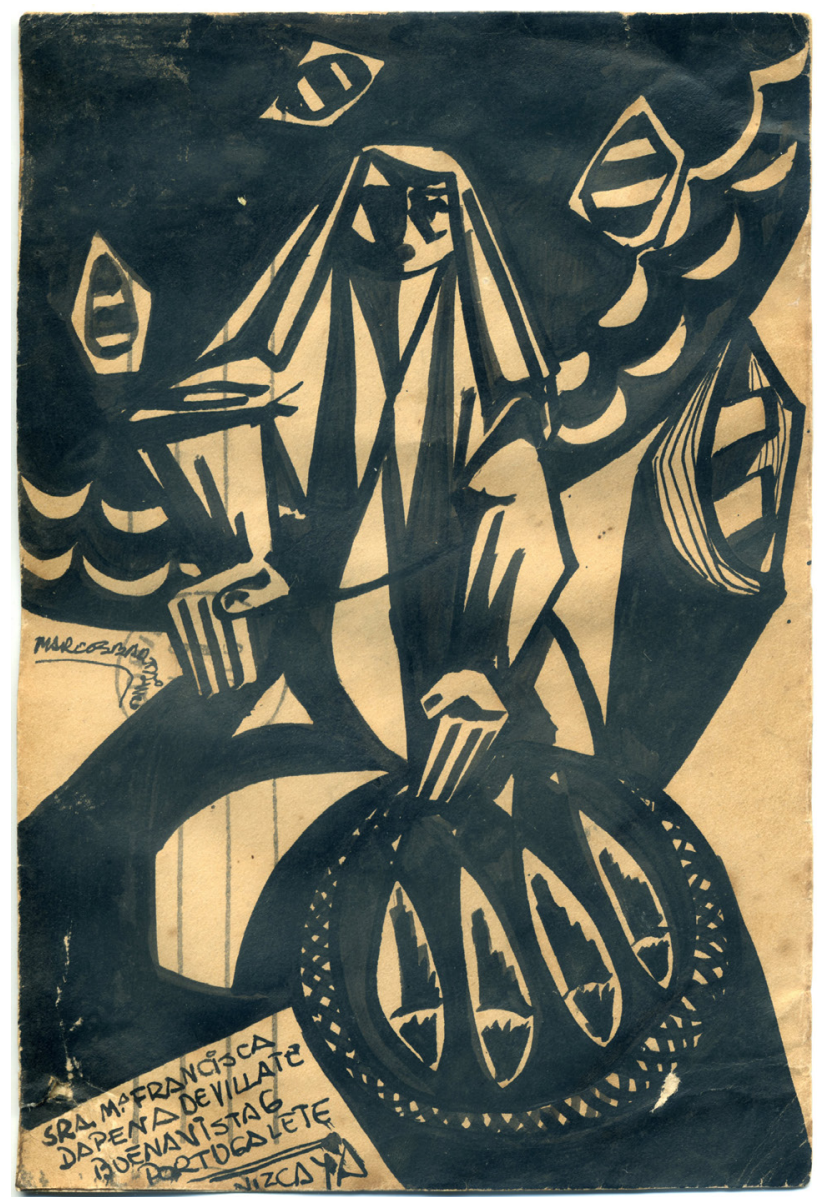

2 María Franciska Dapena, Sin título, dibujo. Estampa Popular de Vizcaya. Hacia 1962. Propiedad de Gaizka Villate Dapena. Aporte de Museo de las Encartaciones-Juntas Generales de Vizcaya

nando el imaginario femenino con su capacidad biológica de reproducción [3]. Entendemos que este interés por el mundo femenino partiría de su propia experiencia como mujer y madre de dos niños pequeños, en combinación con el mensaje del PC con el que simpatizaba, donde la lucha de clases primaba al debate en torno al género. Esto es, de la misma manera que ponía en escena la situación de los trabajadores explotados, el objetivo de estas representaciones femeninas sería el de visibilizar la precariedad de la condición de las mujeres más necesitadas; es decir, no como crítica a las estructuras sociales que propiciaban la desigualdad entre sexos, sino queriendo destacar que la opresión de clase afectaba también a las mujeres. Ejemplo de esta misma necesidad por introducir a las mujeres en la 


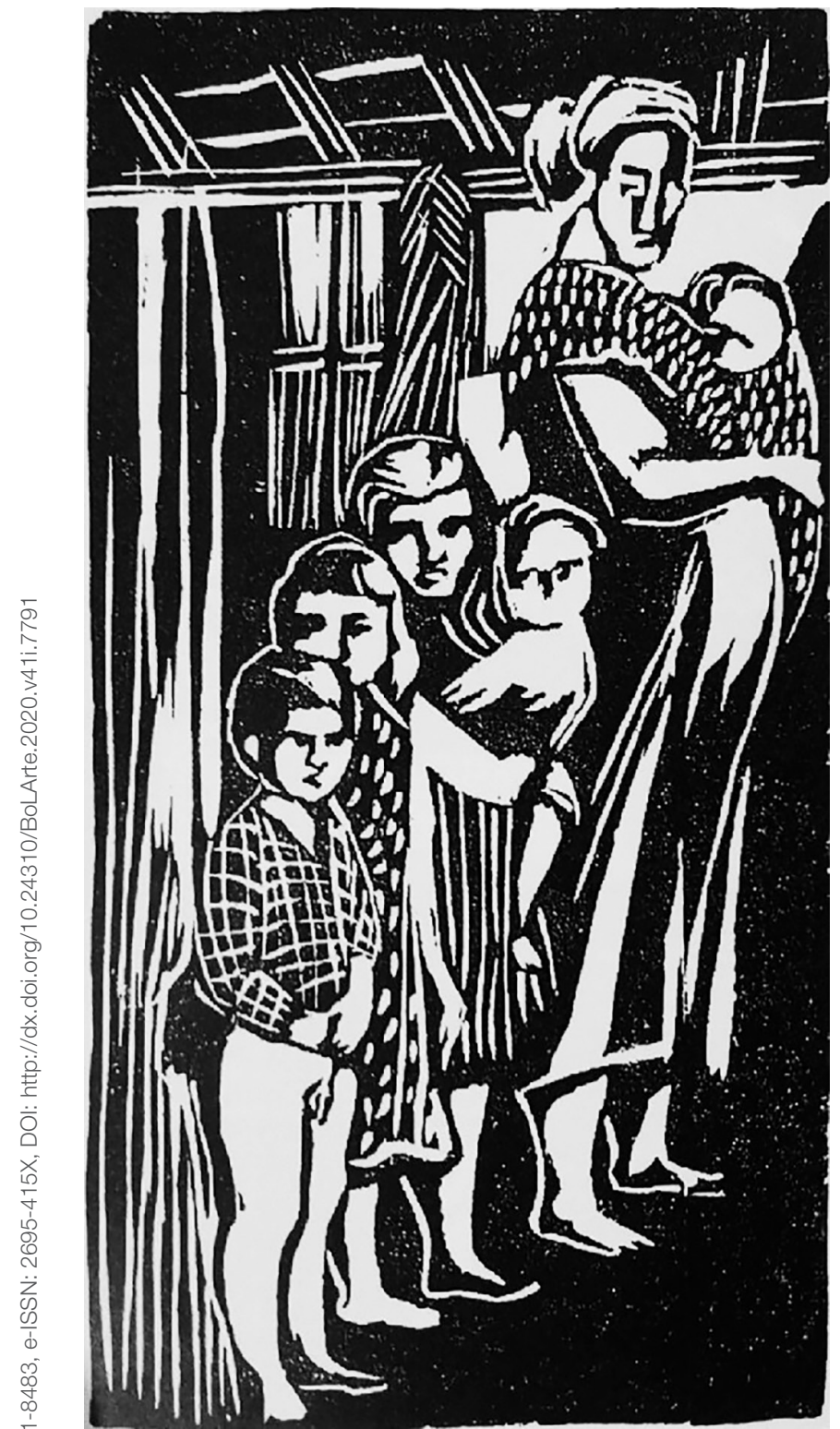

3. María Franciska Dapena, Sin título, linograbado sobre papel. Estampa Popular de Vizcaya. Hacia 1962

problemática social lo encontramos en el poema «Mujeres de España» ${ }^{13}$ de Sabina de la Cruz que acompañó el catálogo de la primera exposición de Estampa Popular de Vizcaya (1962), celebrada en San Sebastián. No obstante, en este caso, más allá de visibilizar y presentar a las mujeres como víctimas de la represión franquista, la poeta también criticaba el rol que aquella sociedad había designado a las mujeres; es decir, el de ser cuerpos reproductores destinados al servicio del hogar y la religión que, además, eran víctimas de las estructuras sociales de clase. Por lo tanto, manifestaciones iniciales como estas son muestra de la preocupación de ambas por introducir el mundo de las mujeres y la agencia femenina ${ }^{14}$ como una cuestión importante a tratar en su práctica política y artística.

Resulta necesario, por otra parte, considerar la forma en que negoció María Dapena el papel de artista y militante comunista con el rol femenino que establecía la sociedad franquista, y relacionar esta experiencia con la visión feminista de carácter esencialista a la que hemos hecho mención. Por ejemplo, es sabido que el espacio doméstico de Dapena y Villate fue punto de encuentro habitual en las reuniones de intelectuales, artistas y militantes ${ }^{15}$. Es decir, el compromiso político y la condición clandestina se combinaban con el papel femenino del cuidado y el espacio doméstico como campo de actuación. Asimismo, no es de extrañar que fueran pocas quienes participaran activamente en estos ambientes artísticos o políticos comprometidos, principalmente por ser incompatible con el papel otorgado a las mujeres en la sociedad franquista, pero también por la sólida estructura patriarcal que mantenían estas mismas colectividades. Razón por la cual, dentro del círculo de intelectuales que compartía Dapena en este periodo, las pocas compañeras presentes en este espacio guardaron la similitud de ser parejas sentimentales de hombres comprometidos de izquierda. Ese fue el caso de la poeta Sabina de la Cruz, compañera sentimental de Blas de Otero a partir de la década de los sesenta, o Mari Luz Bellido la pareja de Agustín Ibarrola ${ }^{16}$. De modo que la posición de acompañantes les facilitó el acceso a las reuniones y tertulias que organizaban en lugares públicos como el Café Mauri, y años más tarde en el de La Concordia, ambos en el centro de Bilbao ${ }^{17}$.

En cuanto a cuál era la participación femenina en el PC de estos años, en líneas generales, las mujeres fueron relegadas a tareas auxiliares como la confección y la distribución de propaganda, la recaudación de dinero o al papel de ser figuras de enlace (Moreno, 2014). Es cierto que la implicación de María Dapena con el partido fue muy seria ${ }^{18}$, también en su faceta artística ${ }^{19}$. Aun así, también realizó tareas de vigilancia, valiéndose del rol apolítico que venían a representar las mujeres; por ejemplo, Ibarrola recordaba cómo su mujer y Dapena recopilaban información sobre el movimiento obrero y los paros de las fábricas en Bilbao que después 
él remitía a una agencia de Madrid²0 (Angulo, 1978: 143). Exactamente fue por esta acción como, junto a otros componentes del grupo entre los que se encontraba su marido Gonzalo Villate, María Dapena fue detenida.

\section{La importancia de armar un «nosotras»}

A causa de esta denuncia, el 15 de junio de 1962 María Dapena fue arrestada, acusada de pertenecer al PC y juzgada por un Consejo de Guerra, amparada en una ley de estado de excepción ${ }^{21}$. Así, la artista fue trasladada a Madrid, primero a la cárcel de mujeres de las Ventas y después, a la de Alcalá de Henares, donde pasó dos años. Apoyándose en las notas que fue tomando en el trascurso de su encarcelamiento, la artista narraría esta experiencia a principios de los años setenta ${ }^{22}$ en el libro jSr. Juez! (soy presa de Franco...), cuya publicación fue posible en 1978

Precisamente, en relación al interés del artículo, fue en los años de prisión cuando Dapena se hizo más consciente de la estrecha relación que existía entre las acciones criminales y las injusticias sociales, pero sobre todo de la posición desigual que la sociedad confería a las mujeres ${ }^{23}$. Al tratarse de una prisión femenina, compartir espacio y establecer amistad no solo con presas políticas como ella, sino con encarceladas comunes, la artista fue tomando cada vez más conciencia sobre la explotación que el sistema ejercía sobre estas mujeres. Por ello, la citada autobiografía se presentaba como un alegato contra esta opresión ${ }^{24}$. Así, por ejemplo, a lo largo del libro replicaba reiteradamente la injusticia que suponía que las prostitutas fueran las arrestadas y no sus chulos o clientes ${ }^{25}$; pero también manifestaba la falta de libertad y la omnipresente estructura patriarcal de la sociedad, aunque no utilizara tal término, sino que lo relacionara con el sistema capitalista y la moral impuesta por el franquismo ${ }^{26}$.

Por lo tanto, es evidente cómo en la década de los sesenta -desde la experiencia de la prisión hasta que escribe el libro- la artista vizcaína fue adquiriendo una clara conciencia feminista que trataré de contextualizar con el momento vital e histórico al que pertenece. En primer lugar, como decía, la experiencia en el penal supuso un factor clave. El espacio de la prisión a principios de los sesenta aglomeró mujeres de generaciones y realidades muy diferentes. Jóvenes detenidas por manifestarse a favor de la amnistía de los presos políticos o mujeres políticas, como María Dapena o también la artista Jacinta $\mathrm{Gil}^{27}$, arrestadas por lo que sería la última ola represiva del franquismo, compartieron espacio con presas comunes o con presas políticas de generaciones anteriores. Por ello, como mencionaba Ricard Viyes, aunque el objetivo del encarcelamiento político fuera precisamente la anulación del pronombre personal «nosotras», el espacio de la cárcel fue importante para la gestación y la concienciación de este (2004: 19). La vivencia de María Dapena así lo demuestra.

Por otra parte, además de la fuerte experiencia que supuso la prisión, la conciencia feminista vendría ligada también al momento histórico y a los ambientes intelectuales en los que se desenvolvió la artista. Como ha sido estudiado, las primeras movilizaciones feministas en España en los años sesenta, aunque no como una acción del partido, sí que tuvieron relación con el PC. Por ejemplo, entre los diferentes grupos femeninos que fueron surgiendo, en 1965 se creó el Movimiento Democrático de Mujeres -el MDM-, en el cual, aunque albergaba diferentes conciencias políticas, la mayoría de sus participantes fueron militantes comunistas y estuvo promovido por el PC y el PSUC (Moreno, 2014). No obstante, para dichos partidos el camino para acabar con la opresión femenina seguía siendo aquel que marcaba la ortodoxa doctrina marxista, esto es, con la derrota definitiva del capitalismo y las clases sociales. Una vez abolida la estructura, la discriminación de las mujeres desaparecería. De ahí que en estos inicios el Partido Comunista, interesado en movilizar la mayor masa popular posible, asumiera las demandas de las mujeres como una nueva materia a añadir en sus reivindicaciones generales, no como una problemática específica (López, 2012).

En este punto, conectando el caso de Dapena con las primeras movilizaciones feministas, es interesante recurrir a la relación y al debate intelectual que mantuvieron la artista y Lidia Falcón. Las dos mujeres establecieron amistad a causa de la estrecha relación que habían tenido sus respectivas parejas en el penal de Burgos, amistad que mantuvieron una vez liberados ${ }^{28}$. Desde ese momento, fue habitual que se vieran en sus respectivos domicilios de Santurce y BarceIona. Para entonces, Lidia Falcón se había dado a conocer como activista feminista, habiendo publicado el libro Los derechos civiles de la mujer: texto, jurisprudencia y comentarios (1963) y siendo miembro activo del MDM en Barcelona. Defensora de un feminismo radical, fue crítica con la posi- 


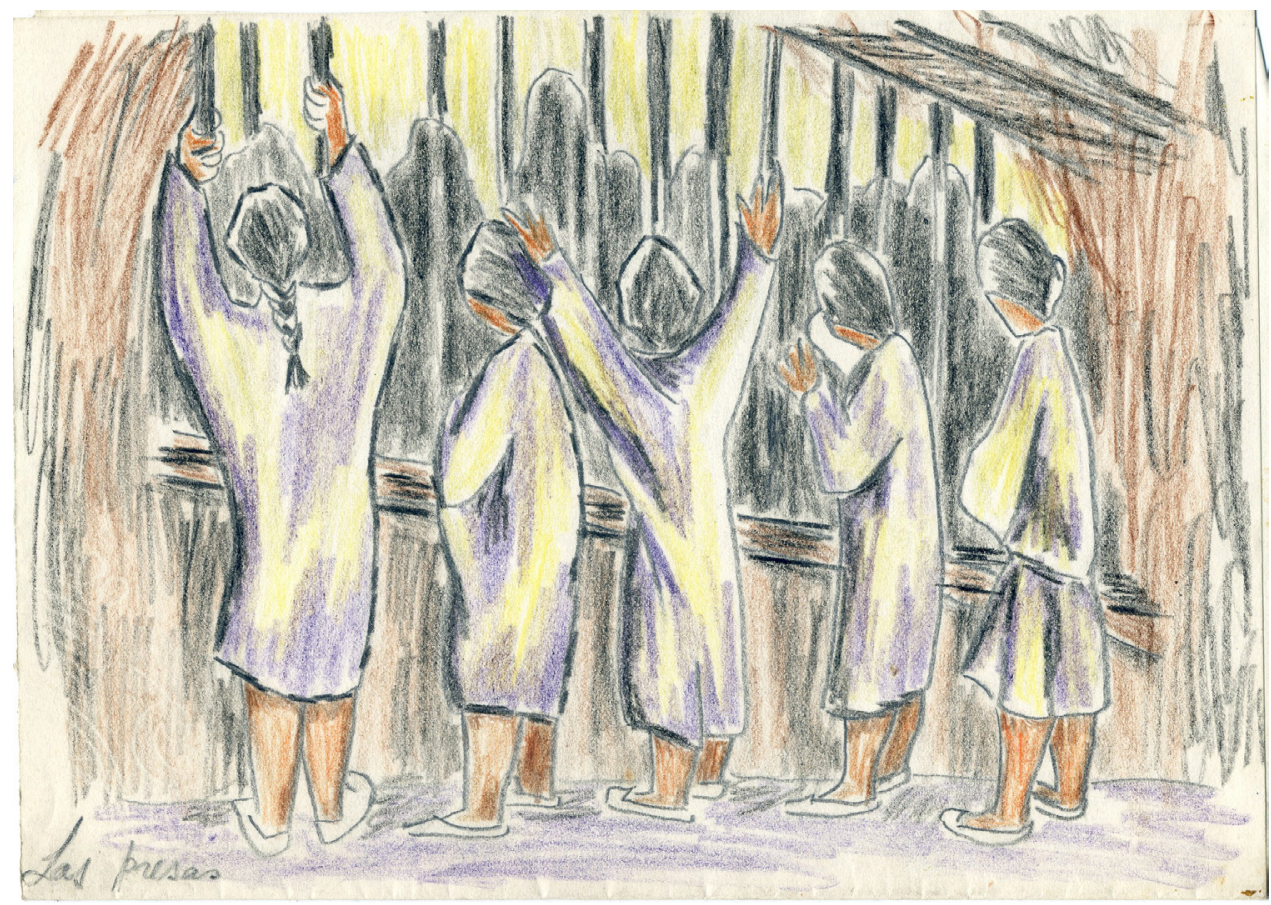

4. María Franciska Dapena, Presas, dibujo. Década de los setenta. Propiedad de Gaizka Villate Dapena. Aporte de Museo de las Encartaciones-Juntas Generales de Vizcaya

ción que presentaba el PC en torno a la problemática femenina ${ }^{29}$, postura que, por el contrario, María Dapena defendía. En efecto, la artista se identificaba como feminista pero dentro de los parámetros que marcaba su partido. No compartía la tesis de Falcón de entender a la mujer como clase, sino que apoyaba la idea de que la discriminación de la mujer debía introducirse como un asunto inherente a la lucha general de clases, la cual afectaba a todas las personas ${ }^{30}$. Sin embargo, aparte de sus diferencias políticas ${ }^{31}$, la relación entre ambas fue muy directa y la conciencia feminista que la artista fue desarrollando en estos años debe ligarse sin duda a este vínculo. Así, por ejemplo, Falcón recordaba que en 1968 incorporó a Dapena en una serie de conferencias en defensa de los derechos de la mujer que organizaba la Junta de la Directiva de la Asociación de Amigos de Naciones Unidas en Barcelona ${ }^{32}$.

De la misma forma, esta toma de conciencia y desarrollo intelectual y político que vivió Dapena se vería reflejado también en su práctica artística. Por ejemplo, si atendemos a las obras que dedicó al tema de la prisión, estas se identifican con la misma mirada feminista que encontrábamos en su autobiografía, siendo la mayoría de ellas, al igual, realizadas después de su liberación ${ }^{33}$. Estas figuras femeninas, por lo general, se presentaban sin rostro, indefinidas y amontonadas, siendo representaciones no de compañeras específicas ${ }^{34}$, sino de la propia condición femenina, lo cual nos remite necesariamente a expresiones suyas como: «no soy más presa que las que ahora caminan por la calle, que, por ser mujer, nací presa» (Dapena, 1978: 97). Lo mismo ocurría con las representaciones de las trabajadoras o las recurrentes escenas de maternidad, las cuales muestran la preocupación de la artista por describir y denunciar, al igual que lo haría a través de sus palabras, la condición desigual que otorgaba aquella sociedad a las mujeres. Argumento de este cambio de visión se evidenciaría en que, al contrario de las obras realizadas antes de la prisión, ahora el registro temático se reducía casi exclusivamente a visibilizar la situación de las mujeres [4], [5] y [6].

Asimismo, resulta interesante cómo el camino trazado por María Dapena hacia la crítica -literaria y plástica- de la opresión femenina es equiparable a la dirección tomada por otras artistas vinculadas también al realismo social. Ese 
5. María Franciska Dapena, Presas, dibujo. Década de los setenta. Propiedad de Gaizka Villate Dapena. Aporte de Museo de las EncartacionesJuntas Generales de Vizcaya

6. María Franciska Dapena, Presas, dibujo. Década de los setenta. Propiedad de Gaizka Villate Dapena. Aporte de Museo de las EncartacionesJuntas Generales de Vizcaya
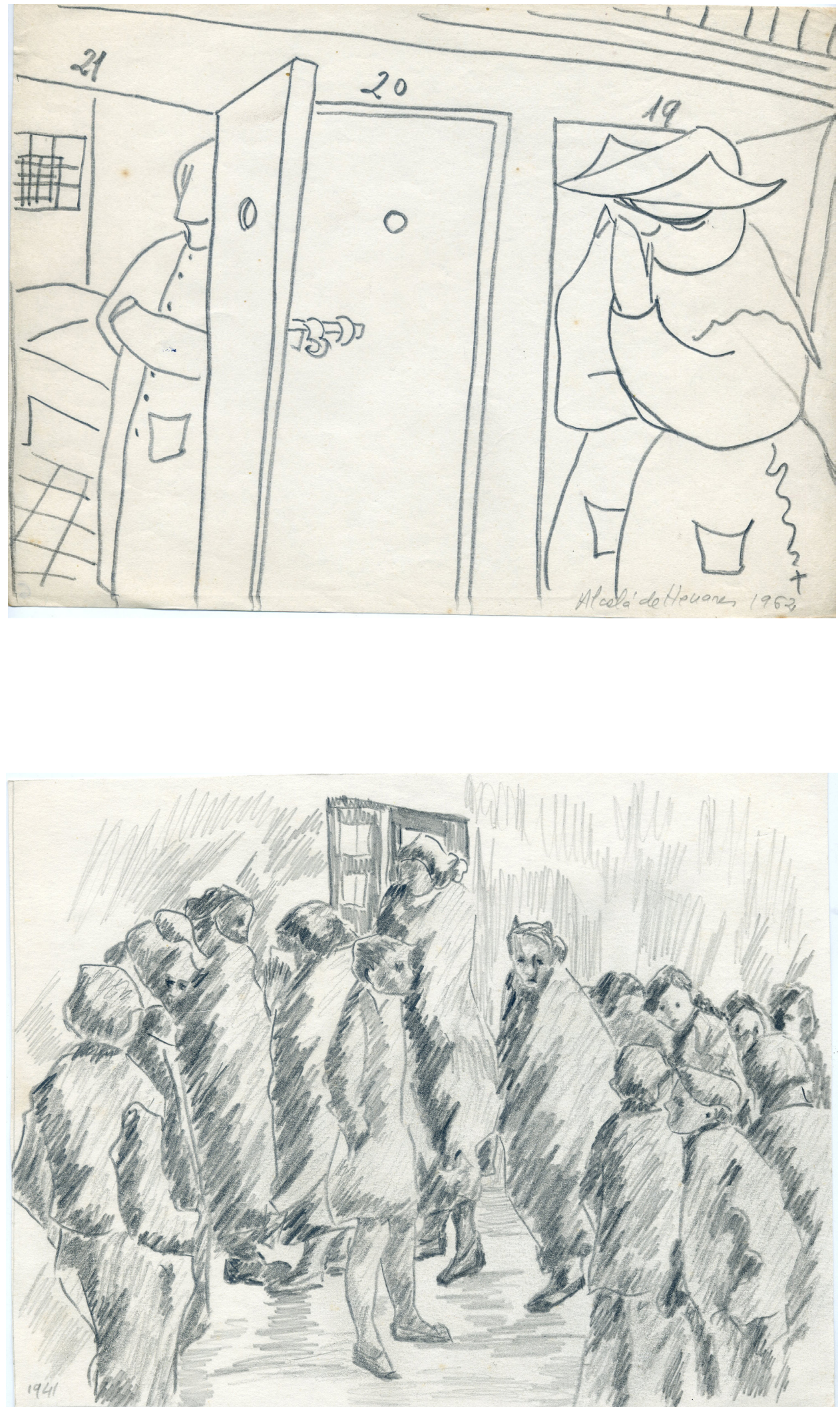

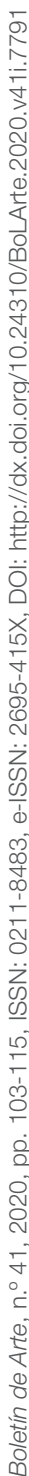




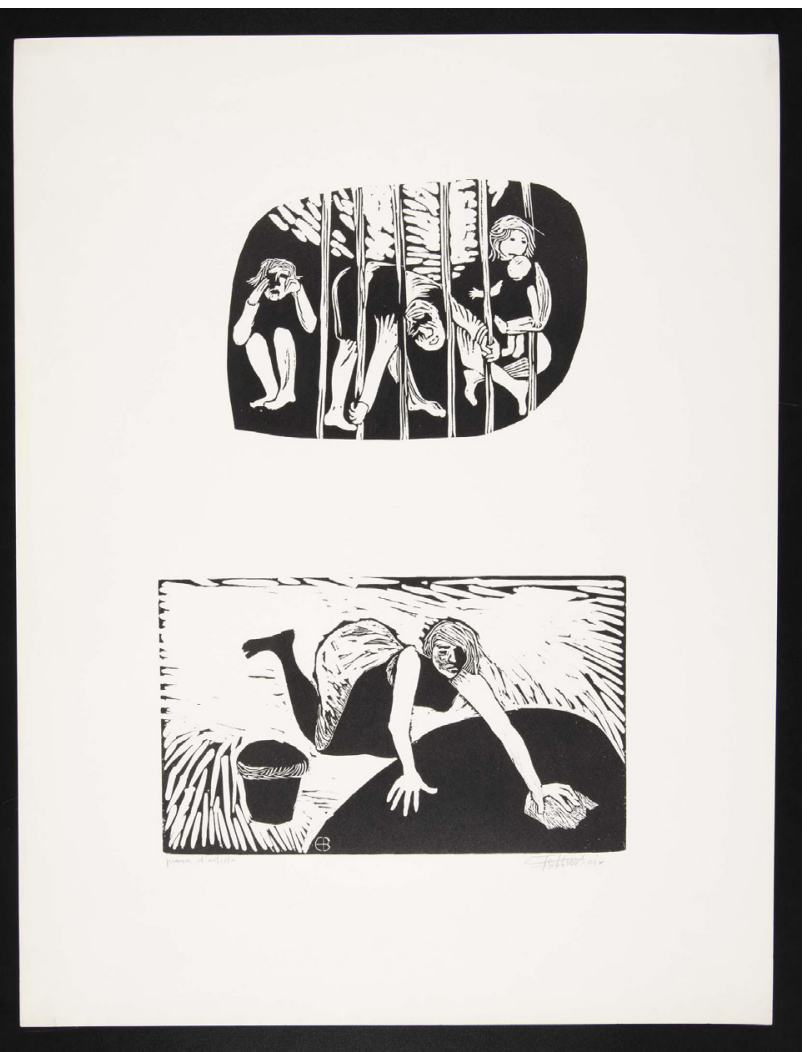

7. Esther Boix, Dona que frega i els fills tancats, linograbado sobre papel. Estampa Popular Catalana. 1965-1966. Museo Nacional Centro de Arte Reina Sofía

fue el caso, por ejemplo, de Esther Boix, miembro de Estampa Popular de Cataluña, quien a través de sus grabados planteaba una denuncia visual de las duras condiciones laborales de las mujeres, el mundo de la cárcel, el trabajo doméstico o el modelo de maternidad impuesto por la sociedad [7]. En contra del ideal de la mujer trabajó también la integrante de Estampa Popular de Valencia Ana Peters, en su caso, empleando como estrategia de denuncia los estereotipos femeninos difundidos en los medios de comunicación y la cultura de masas (De Haro, 2013) ${ }^{35}$. Al fin y al cabo, no es de extrañar que las artistas integrantes de los colectivos artísticos antifranquistas se sintieran apeladas por las demandas feministas que fueron surgiendo en sus entornos y, por tanto, llevaran estas nuevas conciencias políticas a sus planteamientos artísticos. En relación a esta idea, es pertinente mencionar cómo en estos inicios, la implicación del PCEEPK con el movimiento feminista no fue tan directa como en
Barcelona o Madrid ${ }^{36}$. De ahí que Lidia Falcón recordara que en aquellos años de clandestinidad, el PCE-EPK era «machista a morir, mucho peores que los catalanes» ${ }^{37}$. La misma Dapena fue crítica con la estructura machista de su partido y con la repercusión que ello tuvo en su carrera ${ }^{38}$. Al fin y al cabo, debemos recordar que el discurso generado por los críticos de arte mencionados al inicio del artículo suponía la realidad a la que se enfrentó Dapena en su entorno más cercano. «La organización tomó a Agustín Ibarrola como el pintor oficial del partido, mientras que a Dapena no la promocionaron, ni apoyaron en su trabajo artístico» mencionaba Falcón ${ }^{39}$. Una marginación de la que, como decía, ella fue consciente. "A Javier Sáenz de Gorbea le dedico esta recopilación de algunas de mis cosas. Esperando un criterio objetivo, un saludo cordial» [8] escribía Dapena al historiador del arte, agradeciendo el interés que había mostrado por su trabajo pero, tal vez, transmitiendo también su deseo de revisar los discursos parciales.

\section{Otros caminos políticos}

Al inicio mencionaba que el interés presentado por la historiografía hacia la obra de María Dapena se ha centrado casi exclusivamente en su etapa como integrante de Estampa Popular de Vizcaya. Sin embargo, desde otras miradas válidas como la feminista, las propuestas que realizó la artista en los años setenta resultan igualmente de gran interés. Por una parte, en la construcción de nuevas genealogías feministas, es importante resaltar el papel que tomó María Dapena como figura de referencia para una nueva generación de mujeres artistas en Vizcaya. Por ejemplo, es destacable que fuera ella quien enseñó a Sol Panera -quien siguió los fundamentos de Estampa Popular de Vizcaya- la técnica de la xilografía, así como los principios del feminismo. En efecto, Panera recordaba cómo la primera vez que escuchó hablar sobre el pensamiento feminista fue gracias a los encuentros que realizaba Dapena de forma clandestina en su casa, donde Lidia Falcón era la invitada y acudían pocas mujeres interesadas como ella ${ }^{40}$. Una herencia artística y política que quedaría reflejada en su obra [9]. Al fin y al cabo, la visión feminista que fue desarrollando Dapena a lo largo de estos años quedaba plasmada no solo en su producto final, sino en su manera de hacer las cosas. Por ejemplo, es destaca- 


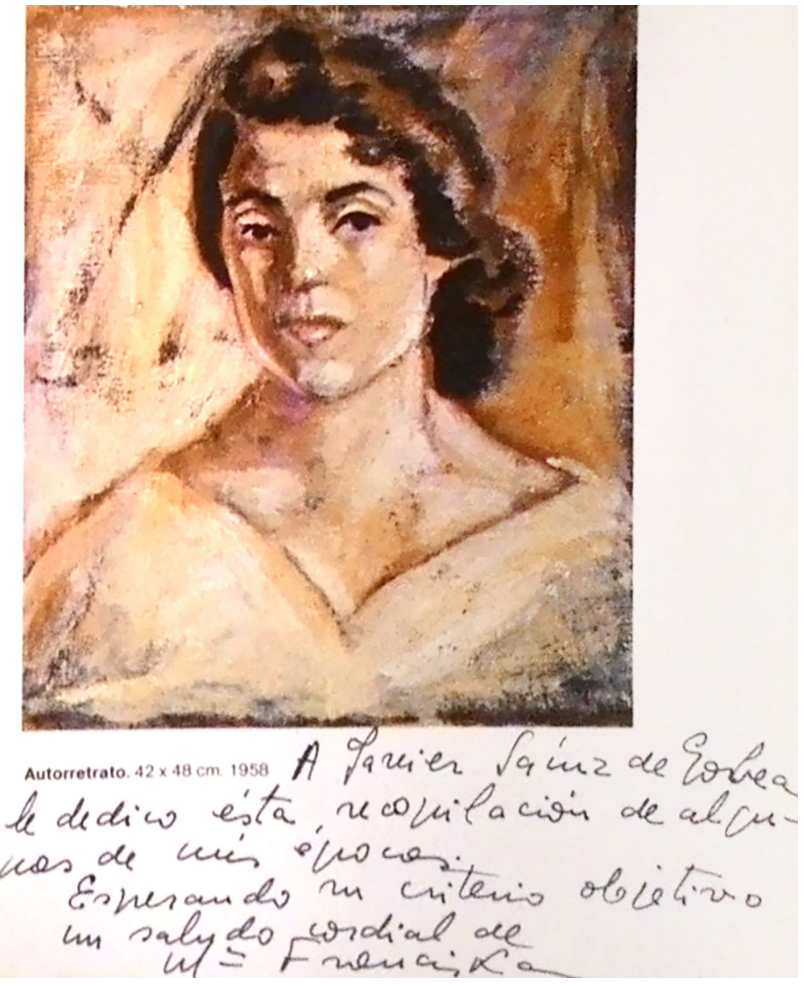

8. Manuscrito de María Franciska Dapena. Propiedad de Gaizka Villate Dapena. Aporte de Museo de las Encartaciones-Juntas Generales de Vizcaya

ble que dentro del último grupo artístico al que perteneció, Indar (1970) ${ }^{41}$, el cual funcionó gracias al sustento de la galería Arteta de la misma Dapena, la mayoría de las participantes fueran mujeres de una generación más joven ${ }^{42}$. Un hecho inédito en la historia de los colectivos artísticos del País Vasco.

Por otro lado, a pesar de su claro compromiso por la igualdad y aun ella misma criticándolo, en su vida personal se vio obligada a mantener el papel tradicional de madre, esposa y trabajadora del hogar. Su hijo Gaizka recordaba frases de su madre como: «Picasso tendría quien le barriera la casa, yo no» ${ }^{43}$. $\mathrm{O}$ en la misma línea, afirmaciones como la siguiente:

Pinto poco porque soy mujer y las mujeres llevamos dos alienaciones: si permanecemos solteras, nadie te exime de los trabajos «propios de la mujer» y no te sirve de nada decir que tratas de lograr tu profesión. [...] He matrimoniado y la responsabilidad de un hogar y dos hijos varones con unos

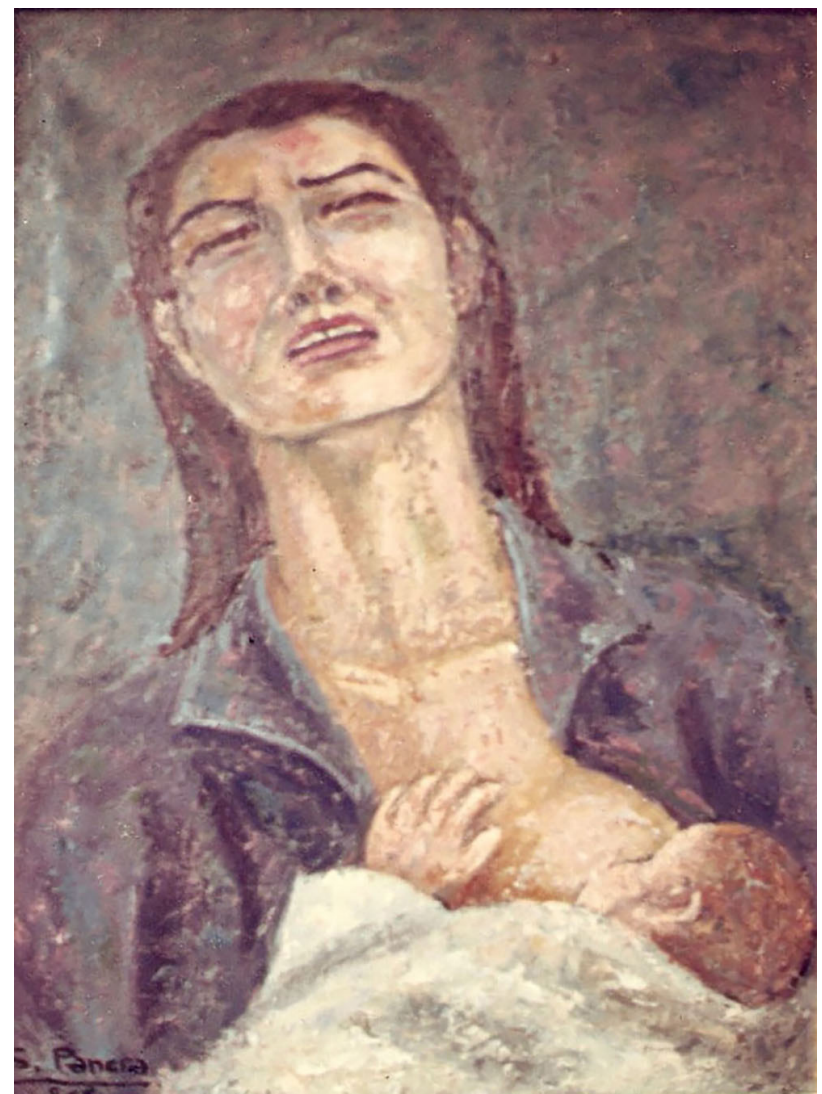

9. Sol Panera, Maternidad, óleo sobre lienzo. 1973. Propiedad de la artista

valores insoslayables tiran de mí contra mi vocación y mis enormes propósitos (Marrodán, 1971).

A mediados de los años setenta, en paralelo a los cambios que se fueron generando en la sociedad y, más específicamente, en el círculo político cercano a la artista, Dapena se fue alejando -no solo geográficamente- del ambiente artístico y político de Bilbao; hechos que propiciaron el cambio drástico en su obra. Las imágenes realistas de denuncia que hasta entonces habían sido habituales en el repertorio de la artista, fueron evolucionando hacia escenas más intimistas y oníricas donde se mostraban sus dos nuevos focos de interés: el ecologismo y el feminismo, este último ahora de una manera más decidida (Barrio y Pereda, 2016b: 2-3) ${ }^{44}$. Por lo general, las nuevas escenas pictóricas se caracterizaban por representar figuras femeninas que se entremezclaban o eran absorbidas por la naturale- 


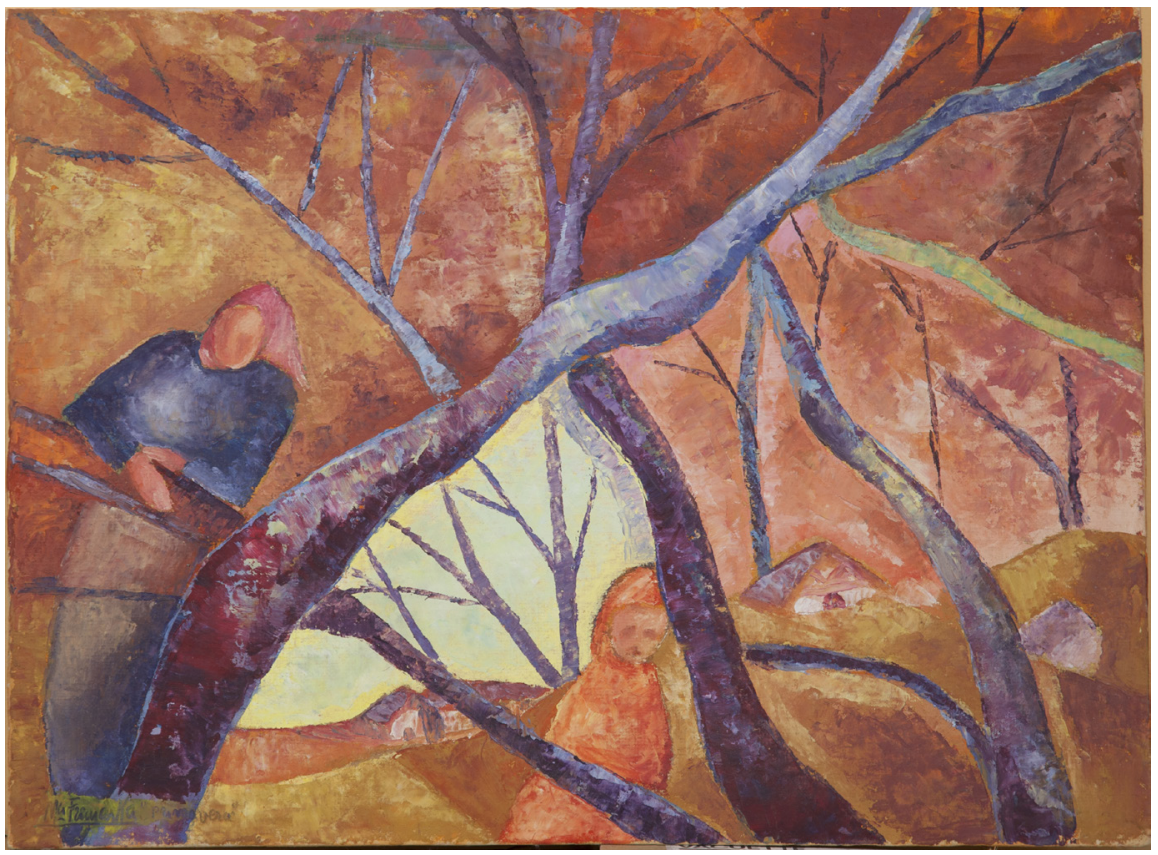

10. María Franciska Dapena, Sin título. Década de los ochenta. Propiedad de Gaizka Villate Dapena. Aporte de Museo de las Encartaciones-Juntas Generales de Vizcaya

za. Estas mujeres, nuevamente, se mostraban sin detalle, recordando el mecanismo empleado anteriormente por la autora, el cual posibilitaba desprenderse de lo anecdótico para así hacer referencia a la misma condición femenina [10]. La misma evolución se reflejaría en su producción literaria, siendo claro ejemplo de ello el libro Vida y muerte enfrentadas. Mujeres de la vida, publicado a principios de los ochenta ${ }^{45}$. Al igual, es significativo que ya alejada del sistema artístico bilbaíno, una de las últimas veces que expuso públicamente fuera en la exposición Emakumeak/Mujeres celebrada en 1989 en la Caja de Ahorros Municipal de Bilbao ${ }^{46}$. De modo que se podría decir que el carácter y la conciencia política que marcó toda la obra y carrera de María Dapena no se difuminaron en su última etapa, sino que tomó otras vías de actuación.

\section{Conclusiones}

La trayectoria de Dapena evidencia la posibilidad de establecer lazos entre las propuestas artísticas etiquetadas como antifranquistas con otras reivindicaciones sociales, como fueron los inicios del movimiento feminista. Aunque fuera infravalorada y obviada por la crítica del momento y también por la historiografía posterior, en gran parte de la producción de María Dapena de a partir de mediados de los años sesenta, se percibe una preocupación por describir y denunciar la situación de la mujer como un asunto de interés político. De ahí que Marzo y Mayayo afirmaran que en las obras de algunas artistas del realismo crítico existiera un «aliento protofeminista» (2015: 298).

No obstante, como decía, la historia del arte español y vasco "oficial», la cual se fue conformando a partir de los años de la Transición, no se interesó por este legado artístico asumido como demasiado viejo, aburrido y militante (Marzo y Badia, 2006). De modo que frente a este vacío crítico, la forma que tomó el relato del realismo crítico fue la de ser una historia evolutiva, donde el supuesto progreso estilístico y temático finalizaba con la entrada de la democracia, siendo esta la última y verdadera culminación del progreso político. Bajo esta visión, todas aquellas prácticas artísticas que una vez abolido el franquismo siguieron ligadas a las reivindicaciones sociales, como fueron las feministas, no entraron en los parámetros que la historiografía 
oficial marcó como «arte político» (De Haro, 2013: 152-153). De manera que será esta indiferencia por parte de la crítica del momento y su posterior lectura, la que explique la brecha generacional que se establece entre estas primeras propuestas artísticas «protofeministas», como las de María Dapena o Sol Panera, y aquellas que saldrían a la luz en el País Vasco generalmente a partir de los años noventa. Por no tener conocimiento de sus antepasadas, sin modelos a seguir, cada nueva generación de mujeres artistas se han visto obligadas, tal y como en su momento hizo María Dapena, a comenzar sin referentes femeninas y a crear nuevos grupos de apoyo.
Anexo

Poema «Mujeres de España». Sabina de la Cruz

\author{
Lentas \\ mujeres de silencio. \\ De la era a casa, \\ de la casa al templo. \\ Rezando \\ pariendo \\ beldando...
}

Todo se lo lleva el viento!

\section{Notas}

1 Sobre la relación entre la crítica comprometida y los colectivos artísticos véase: De Haro, 2010; Barreiro, 2014a y 2014b

2 En esta línea: De Haro, 2013; Marzo y Mayayo, 2015: 298-303.

3 Ha sido Noemí de Haro con su tesis publicada en el libro Grabadores contra el franquismo, además de otras publicaciones, quien más ha investigado el conjunto de Estampa Popular. También son destacables las aportaciones de Leire Makazaga y Alice Cearreta en torno a Estampa Popular de Vizcaya y el papel de María Dapena.

4 Hasta el momento, la muestra más completa ha sido la exposición celebrada en 1996 en el IVAM. Véase: Gandía, 1996.

5 Véase: Barrio y Pereda, 2016a; Barrio y Pereda, 2016b; Barrio y Pereda, 2019

6 El Museo Nacional Centro de Arte Reina Sofía adquiría en 2010 dos estampaciones realizadas ex profeso para la exposición celebrada en 1996 en el IVAM (Cearreta, 2017).

7 Principalmente, hago referencia a las exposiciones: Grupo Danok. 1966-1967, Museo de Navarra (2018) y Después del 68. Arte y prácticas artísticas en el País Vasco 1968-2018, Museo de Bellas Artes de Bilbao (2018).

8 Por ejemplo, aunque el Movimiento de la Escuela Vasca (1966) haya sido fundamental para el discurso histórico oficial generado en el País Vasco, todavía no se han llevado a cabo investigaciones detalladas en torno al subgrupo Emen, colectivo al que perteneció Dapena como única integrante femenina de todo el movimiento.

9 Barrio y Pereda dedican una extensa introducción a la vinculación política de la familia Dapena, la experiencia en la Guerra Civil y la influencia que ello tuvo en la concienciación de la artista (2016a: 6-20).

10 Como la I Bienal Hispanoamericana de Arte (1951), la Exposición preparatoria del Cantábrico para la /I Bienal Hispanoamericana (1954) o la III Bienal Hispanoamericana (1955).

11 En torno a la dimensión técnica y al proceso de trabajo de los artistas integrantes de Estampa Popular de Vizcaya véase: Cearreta, 2017.

12 Siglas del Partido Comunista de Euskadi-Euskadiko Partidu Komunista

13 Anexo.

14 Como explica De Haro, en esta misma exposición Dapena acompañó la estampa Puentes con un poema de Ángela Figuera Aymerich. Un gesto significativo teniendo en cuenta que lo habitual en otros grabadores fue la referencia a Antonio Machado o Miguel Hernández (2010: 183).

15 Por ejemplo, Agustín Ibarrola recordaba que «hacían unas tortillas, una merienda... y nos mantenía unidos». Entrevista realizada por Javier Barrio y Arantxa Pereda a Agustín Ibarrola. 04-2015.

16 Mari Luz Bellido había participado como pintora en algunas exposiciones de la Asociación Artística Vizcaína a inicios de la década de los cincuenta, no obstante, dejó su producción para dedicarse a la vida familiar y acompañar a su pareja.

17 Entrevista realizada por A. Lekuona a Sol Panera. Bilbao, 03-07-2019.

18 Entrevista realizada por Javier Barrio y Arantxa Pereda a Agustín Ibarrola. 04-2019.

19 Por ejemplo, De Haro menciona que Dapena realizó ilustraciones para la publicación clandestina Nuestra Bandera en 1963 (2010: 390$).$

20 Ibarrola realizaba informes para enviar después esta información a Radio España Independiente y otras agencias de noticias extranjeras (De Haro, 2016).

21 En el libro se narra la experiencia de la detención: Dapena, 1978: 7-10. La noticia fue trasmitida por el periódico de filiación comunista España Popular, en México (15-04-1963, p. 3).

22 Su hijo Gaizka Villate calcula que el libro fue escrito hacia 1971-1972. Entrevista telefónica realizada por A. Lekuona a Gaizka Villate. 13-11-2019.

23 Ibidem. 
24 «QQué sentido tendría mi cárcel si, al liberarme, callo? [...] lucharé por las mujeres peor tratadas de la VIDA, las que la sociedad castiga y sostiene sin ellas saberlo» (Dapena, 1978: 82).

25 «¿Por qué la policía cuando llega a un mueblé, encontrando 'in fraganti' a la pareja deja libre al hombre y encarcela a la mujer? [...] ¿A quién se le ocurrió que el pecado puede estar solamente en la mujer? Solo al juez, que, por añadidura, es hombre y si no se le ocurrió a él abundó y redactó la ley con mucho más delito que su inspirador» (Dapena, 1978: 78).

26 «¿No tengo derecho a defenderme yo también diciendo lo que pienso sobre las leyes, la historia escrita por hombres y la aplicación de las religiones? ¿Quién les ha dicho que tengo que pensar como ellos si toda mi naturaleza siente de otra manera?» (Dapena, 1978: 115-116).

27 Jacinta Gil fundadora de Estampa Popular de Valencia y parte del grupo Parpalló. Información extraída de: <https://carceldeventas.madrid.es/history/ una-nueva-generacion-de-presas-politicas-en-ventas> (fecha de consulta: 09-01-2020).

28 Fueron puestos en libertad hacía finales de 1965. Entrevista telefónica realizada por A. Lekuona a Lidia Falcón. 31-10-2019.

29 Para más información sobre las vivencias políticas de la escritora y política véase: Falcón, 1999.

30 Por ejemplo, su visión feminista no concebía los principios de la liberación sexual. Interpretaba el lesbianismo que practicaban muchas presas como consecuencia directa de la posición social que les había tocado vivir: «Si las condenadas contraen en el encierro esta deformación sexual hay que culpar a su falta de libertad» (Dapena, 1978: 159).

31 Otro debate político en el que mantuvieron posturas contrarias fue en torno a la posición del partido en referencia a los acontecimientos de Praga de 1968. A diferencia de Falcón, Dapena amparó la decisión de Santiago Carrillo de mantenerse en contra de la entrada de Checoslovaquia al sistema occidental. Entrevista a Lidia Falcón anteriormente citada.

32 Ibidem

33 Entrevista a Gaizka Villate anteriormente citada.

34 En algunas ocasiones detalla a sus compañeras (Barrio y Pereda, 2016b: 5).

35 Además de los trabajos citados hasta ahora, para más información sobre la confluencia entre los discursos feministas y las artistas del realismo social, véase: Rivera y Gaitán, 2012; Folch, 2015; Folch y Tejeda, 2018; Tejeda, 2019.

36 El MDM, por ejemplo, tuvo mucha más resonancia en Madrid o Barcelona que en el País Vasco. El auge de las reivindicaciones feminista en el País Vasco, por lo general, estallarían a partir de 1975, en paralelo a otros movimientos sociales como el nacionalismo, las huelgas de los trabajadores, el ecologismo y las revueltas estudiantiles (Ruiz, 2005).

37 Entrevista a Lidia Falcón anteriormente citada.

38 Entrevista a Gaizka Villate anteriormente citada.

39 Entrevista a Lidia Falcón anteriormente citada.

40 Entrevista a Sol Panera anteriormente citada.

41 Los y las integrantes fueron: Marta Brancas, María Dapena, Miguel Díez Alava, Juan Garro Coldón, Guillermina, Alberto López, Fernando Mirantes, R. Ortiz Alfau, Sol Panera, Consuelo Peciña, Begoña Peciña, Mayalen Urrutikoetxea y Ana Zarrabe.

42 De catorce artistas nueve eran mujeres, todas de una generación posterior, Sol Panera y Begoña Peciña fueron dos de estas. Ambas recuerdan a María Dapena como la figura nuclear del proyecto colectivo. Entrevista realizada por A. Lekuona a Sol Panera y Begoña Peciña. Esta última en Guecho, 07-12-2019.

43 Entrevista a Gaizka anteriormente citada.

44 David Beorlegui analizó cómo muchas de las personas que habían luchado activamente contra el franquismo experimentaron una emoción de desencanto con la manera en que se desarrolló el final de la dictadura y la transición. El autor señalaba asimismo cómo parte de la militancia rupturista se vio atraída hacia otros movimientos que emergieron con mucha fuerza a finales de los años setenta como, por ejemplo, el antinuclear, el feminista o el pacifista (Beorlegui, 2017).

45 El libro venía ilustrado con sus dibujos. Dapena, 1987.

46 María Dapena presentó la obra Vivir realizada en 1978

\section{Bibliografía}

ANGULO BARTUREN, Javier (1978), Ibarrola ¿un pintor maldito?, Haranburu, San Sebastián.

ANÓNIMO (1962), Estampa Popular de Vizcaya: Blanco, Dapena, Ibarrola y Ortega, Asociación Artística Guipuzcoana, Ayuntamiento de San Sebastián, San Sebastián.

ANÓNIMO (1989), Emakumeak/Mujeres, Caja de Ahorros Municipal de Bilbao, Bilbao.

BARREIRO LÓPEZ, Paula (2014a), «El giro sociológico de la crítica de arte durante el tardofranquismo», Desacuerdos, n. ${ }^{\circ} 8$, pp. $16-45$.

- (2014b), «La sombra de Marx. Vanguardia, ideología y sociedad en la crítica militante del segundo franquismo», en BARREIRO LÓPEZ, Paula y DÍAZ SÁNCHEZ, Julián (eds.), Crítica(s) de arte. Discrepancias e hibridaciones de la Guerra Fría a la globalización, CENDEAC, Murcia, pp. 254-274.

BARRIO, Javier (comis.) (2019), Conociendo a María Franciska Dapena/María Franciska Dapena ezagutuz, Museo de Las Encartaciones,

Balmaseda. 
BARRIO, Javier y PEREDA, Arantxa (comis.) (2016a), Mari Dapena. Artista baten konpromisoa/El compromiso de una artista, Museo de Las Encartaciones, Balmaseda.

- (2016b), Mari Dapena. Lerro artean/Entre líneas, Sala de Exposiciones de Juntas Generales de Bizkaia, Bilbao.

BEORLEGUI ZARRANZ, David (2017), Transición y melancolía. La experiencia del desencanto en el País Vasco (1976-1986), Postmetropolis Editorial, Madrid.

BOZAL, Valeriano (1966), "El grabado en España», Realidad, revista bimestral de cultura y política, n. ${ }^{\circ}$ 11-12, pp. 113-125.

CEARRETA-INNOCENTI, Alice (2017), «Estampa Popular de Vizcaya. La creación plástica como instrumento de acción política», Archivo Español de Arte, n. ${ }^{\circ}$ 358, pp. 155-170.

DAPENA, María Francisca (1978), iSr. Juez! (soy presa de Franco...), Haranburu, San Sebastián.

- (1987), Vida y muerte enfrentadas. Mujeres de la vida, Indauchu, Bilbao.

DE HARO GARCÍA, Noemí (2010), Grabadores contra el franquismo, CSIC, Madrid.

- (2013), «Mujeres artistas e imágenes de la opresión femenina en el realismo crítico. Revisando la historia oficial del antifranquismo», en ALIAGA, Juan Vicente y MAYAYO, Patricia (coords.), Genealogías feministas en el arte español: 1960-2010, This Side Up, Madrid, pp. 149-169.

- (2016), «Voces de seda. Las pinturas clandestinas de Agustín Ibarrola (1962-1965)», Archivo Español de Arte, n. ${ }^{\circ} 355$, pp. $299-316$.

FALCÓN, Lidia (1963), Los derechos civiles de la mujer: texto, jurisprudencia y comentarios, Nereo, Barcelona.

- (1999), Memorias políticas (1959-1999), Planeta, Madrid.

FOLCH, María Jesús (comis.) (2015), Ana Peters. Mitologías políticas y estereotipos femeninos en los sesenta, IVAM, Valencia.

FOLCH, María Jesús y TEJEDA, Isabel (comis.) (2018), A contratiempo. Medio siglo de artistas valencianas (1939-1980), IVAM, Valencia.

GANDÍA CASIMIRO, José (comis.) (1996), Estampa Popular, IVAM, Valencia.

GARCÍA-LANDARTE, Valeria (2006), «Estampa Popular de Vizcaya. El realismo social de los años 60 del País Vasco», Ondare, n. ${ }^{\circ} 25$, pp. 393-401.

LÓPEZ HERNÁNDEZ, María Teresa (2011), «El PCE y el feminismo en España (1960-1982)», Investigaciones Feministas, vol. 2, pp. $299-318$. MAKAZAGA, Leire (2014), «La obra gráfica de María Francisca Dapena durante el tardo franquismo y la transición. La única artista integrante de Estampa Popular de Vizcaya», Artigrama, n. ${ }^{\circ} 29$, pp. 433-450.

MARRODAN, Mario Ángel (1971), «Entrevista a María Franciska Dapena», Revista Abra, n. ${ }^{\circ} 14$.

MARZO, Jorge Luis y BADIA, Tere (2006), «Las políticas culturales en el Estado Español (1985-2005)». En: <www.soymenos.net/politica_espanya.pdf $>$.

MARZO, Jorge y MAYAYO, Patricia (2015), Arte en España (1939-2015): Ideas, prácticas, políticas, Manuales Arte Cátedra, Madrid.

MORENO SECO, Mónica (2014), «A la sombra de "Pasionaria". Mujeres y militancia comunista (1960-1982)», en RAMOS, María Dolores (ed.), Tejedoras de Ciudadanía. Culturas políticas, feminismos y luchas democráticas en España, Universidad de Málaga, Málaga, pp. 257-282.

RIVERA MARTORELL, Sara y GAITÁN SALINAS, Carmen (2012), «La polisemia de las imágenes. Un análisis de la obra de Eulalia Grau Discriminaci de la dona (1977) desde la perspectiva del feminismo socialista», Arte y políticas de identidad, n. ${ }^{\circ}$ 6, pp. 45-62.

RUIZ TORRADO, María (2005), «Emakumea Frankismoan», Kondaira, n. ${ }^{\circ}$ 3, pp. 1-34.

TEJEDA, Isabel (comis.) (2019), Fuera del canon. Las artistas Pop en España, MNCARS, Madrid.

VIYES, Ricard (2004), El daño y la memoria: las prisiones María Salvo, Plaza \& Janés, Barcelona. 